\title{
sciendo
}

\section{Life tables estimation for pension system actuarial projection model with insufficient data: case of Republic of Srpska}

\author{
Nikolina Bošnjak \\ Faculty of Economics of University of Banja Luka, Bosnia and Herzegovina \\ nikolina.bosnjak@ef.unibl.org \\ Vesna Prorok \\ Faculty of Economics of University of East Sarajevo, Bosnia and Herzegovina \\ vesna.prorok@ekofis.ves.rs.ba
}

\begin{abstract}
This article provides an upgraded model for actuarial projection of the dependency ratio of the pension fund in the Republic of Srpska. The nonexistence of complete upto-date life tables presents a huge problem of the pension system and life insurance industry modelling in the Republic of Srpska. Therefore, this article tries to encompass the problem by using the life tables of the Republic of Croatia as a starting point for adjustment of age-grouped life tables available for population of the Republic of Srpska. The actuarial projection model for the Pension and Disability Insurance Fund of the Republic of Srpska is upgraded by using these adjusted life tables and the best estimate mortality trend for mortality forecasting. The results of the Republic of Srpska pension fund dependency ratio projections obtained using a forecast of adjusted life tables are compared to the previous research on this topic which used the life tables of the Republic of Serbia for 2013 for the same model. This way we can observe the effect of life expectancy growth on pension fund's dependency ratio estimates as one of the measures of pension fund's sustainability.
\end{abstract}

Keywords: best estimate mortality trend, life tables' adjustment, pension fund dependency ratio.

JEL Classification: G22, H7, J1 1

DOI:10.2478/crebss-2019-0003

Received: December 01, 2018

Accepted: April 02, 2019

\section{Introduction}

The projection of main parameters of a pension fund and the composition of the technical balance sheet, as a useful way of presenting the pension fund's financial sustainability, is regularly done in each European country's state pension fund. The underlying method is based on classical actuarial projection technique (lyer, 1999), while, on the basis of this methodology, each country has developed its own projection model (European Commission, 2009). Starting from the same basic methodology, the first actuarial projection model for the Pension and Disability 
Insurance Fund of the Republic of Srpska was developed and used for projections (Bošnjak, 2016). Given that the state pension fund of the Republic of Srpska is functioning on a Pay as You Go basis, the simple dependency ratio projections are a good indicator of the pension system's sustainability.

The prudent projections of a number of employees and pension benefit users require access to all relevant data of pension fund and among other things have shown to be dependent on future estimates of population and life tables. The significant limitation of previous projections of Pension and Disability Insurance Fund of the Republic of Srpska dependency ratio was the nonexistence of recent life tables for Bosnia and Herzegovina. The last life contingency tables for Bosnia and Herzegovina were done for the period from 1980 to 1982, and are no longer suitable for use due to big demographic changes that have occurred since the eighties. Therefore, the projections from our previous research were made with usage of life tables of Republic of Serbia (Statistical Office of the Republic of Serbia, 2014), but with the assumption of constant death probabilities. It means that the main assumption was that there would be no increase in the expected duration of life during the projection period. In the meanwhile, the life tables of the population of FBiH 2012-2014 (Institute for Statistics of Federation of Bosnia and Herzegovina, 2017) were published, while the complete life tables for a population of Republic of Srpska still have not been calculated. Instead, there are abridged life tables up to the age of 85 for the population of Republic of Srpska that are available from mid of 2018 (Republic of Srpska Institute of Statistics, 2019).

Although the tables for the Republic of Srpska are calculated, due to the short observation period, we are still unable to use them to model mortality projections with well-known Lee-Carter or widely used P-Splines methods. In order to estimate the mortality, trend we need a much longer history of mortality observation. For this reason, as well as for the reason of observing the effect of life expectancy change on the dependency ratio, we will develop rather a simple methodology that will allow us to estimate the projections of life tables of Republic of Srpska using the available complete life table of the Republic of Croatia, which is available at Human Mortality Database (Human Mortality Database, 2000). Beside this, the World Bank's estimates of future mortality in Bosnia and Herzegovina will be used to estimate the trend of mortality, thus mortality projections and increase in life expectancy will be included in the dependency ratio projections. Therefore, as our main hypothesis, we state that the life table modelling and projections are feasible in the countries with insufficient available data, where modern econometric and statistic models cannot be applied. Nevertheless, the widely useful projections can be obtained by the application of rather simple mathematical methods.

In this article, after a short review of literature, we will present the simple methodology, which could be used for abridged life tables of Republic of Srpska, which are expanded according to complete, smoothed life tables of Republic of Croatia and life expectancy and mortality trend extrapolation, when scarce data are available. In the last part of this article, we will present all types of obtained results and compare them to the results of our previous research.

\section{Literature overview}

The developed countries of the European Union have long recognized the need for long-term projections when it comes to planning pension and social policy. The methodologies used to project state pension schemes are based on the classical actuarial projection model (lyer, 1999), while the assumptions underlying each European country methodology are described in the document issued by European 
Commission (European Commission, 2009). Reports on the sustainability of pension system are made based on these methodologies at least every three years. Such reports are used to plan economic, social security and pension policies, as is the case with Germany (Working Group on Ageing Populations and Sustainability, 2017). This paper aims to improve the first model for long-term pension projections of the Pension system of Republic of Srpska (Bošnjak, 2016). The improvement is based on the estimation of projections for mortality tables of the population of Republic of Srpska using the mortality tables of Republic of Croatia with the application of expected life duration of Bosnia and Herzegovina, according to the World Bank estimates (The World Bank Data, 2018). The method applied for the mortality projections could be described as a combination of trend extrapolation and expert opinion methods (Booth, Tickle, 2008). As Waldron considered in his research, the combination of these two methods remains the most widespread projection method by policy planners (Waldron, 2005). Since the intention of this research is to improve the existing actuarial projection model and to make it useful for policy planners, we will rather develop as simple as possible, but practically useful method. The classical models used for expansion of abridged life table, such as Abramowitz and Stegun (Abramowitz, 1965) six-term Lagrangian formula and Heligman-Pollardmodel (Pollard, 1989) are parametric models and thus require the estimation of parameters, which could be technically too demanding for an average policy planner. Thus, we decided to offer a rather simple solution that would be easily applicable, given that the standard complete life table of a similar population is available (Kostaki, 2000). It's long been known that Pay As You Go pension funds are largely driven by demographic trends (Holzmann, 2009) which put a lot of pressure on pension and social plans (ECB Economic Bulletin, 2018). Bearing this in mind, as well as Bismarck's plan that at least three workers will support the retirement of one pensioner, we had an obligation to expand the primarily developed projection model for the Republic of Srpska Pension Fund. In addition, our goal was to estimate its mortality tables, as well as to project the development of mortality during the projection horizon, following the methodology used by the Institute of Actuaries (Institute of Actuaries and Faculty of Actuaries, 1990). Unfortunately, due to insufficient data, we could not investigate the cohort effects on future mortality improvements nor apply stochastic methods proposed by later publications of Institute of Actuaries (Institute of Actuaries, 2004), and this task remains for future improvement of the model.

\section{Methodology}

The model of the actuarial projection for the Pension and Disability Insurance Fund of the Republic of Srpska (Bošnjak, 2016), based on the classic actuarial projection technique, is used as the main model for the projections of the number of employees and pension beneficiaries in the Republic of Srpska. In the article from 2016, projections were made on the basis of analytical data on pension beneficiaries and employees in Republic of Srpska. Used data were related to the data from the December of 2014 and 2015 and were obtained from the Pension and Disability Insurance Fund of Republic of Srpska. Moreover, as the source of a total expected number of active people in the Republic of Srpska, we used the projections of the total population calculated for the needs of the pension system reform in 2011 (The Working Group for the development of the Pension System Strategy in Republic of Srpska, 2010). In addition to these sources, in the original paper, the life-contingency tables of Republic of Serbia for the period 2012-2014 were used. The same set of data and population projections were used as the basis for the projections in this article, so that the comparison of the results of two articles is feasible. The difference consists in the 
application of mortality tables estimated and projected for the Republic of Srpska expected life, which significantly improve the original actuarial projection model for Pension and Disability Insurance fund of the Republic of Srpska.

In order to obtain complete life tables for the population of the Republic of Srpska, we used the procedure for extending the already available abridged life tables (death probabilities). The procedure was carried out using the complete life tables of the Republic of Croatia, and is based on the multiplication of the original probability of a specific age interval with the distribution factor.

Distribution factors are calculated from the complete life tables of Republic of Croatia for the year 2016 and are equal to the quotient between the age-specific mortality probability of Croatia and grouped mortality probability from abbreviated mortality tables of Republic of Croatia. Therefore, with the application of distribution factors on the death probabilities of each age group, the mortality probabilities of the Republic of Srpska will be distributed on age-specific probabilities, according to agespecific distribution of life probabilities of Republic of Croatia. This procedure will ensure that the adjusted life tables give us the life expectancy of the Republic of Srpska while maintaining the distribution of probabilities of death by age within the age groups of the population of the Republic of Croatia. Thus, here is the main underlying assumption that the populations of Republic of Croatia and Republic of Srpska share the same age distribution of death probabilities, which can be accepted given that the mortality probabilities and life expectation do show regional tendencies and characteristics. Moreover, a more appropriate approximation would be the usage of average death probabilities distribution for the whole region (hence, including the life tables of Serbia and the Federation of Bosnia and Herzegovina), but unfortunately, due to unavailability of the data, we will have to restrict only to the Croatian life tables.

Upon the adjustment of mortality tables, the best-estimated mortality trend is used for calculation of projections of age-specific death mortalities for the next 50 years.

The trend estimation was based on ordinary linear trend extrapolation:

$$
f(x)=\sqrt[p]{\frac{q(x ; t)}{q(x ; t-p)}},
$$

where $f(x)$ is the age $(x)$ specific trend factor for given sex and $q(x ; t)$ is the age-specific probability of death for given sex in period $t$ or $t-p$.

With the use of trend factors estimated in this way, it is easy to obtain the projections of mortality tables for the following 50 years.

$$
q(x ; t+j)=q(x ; t) * f(x)^{j} .
$$

The problem with the best-estimated trend is that the projections of probabilities of death are estimated to decrease exponentially, causing the life expectancy to grow, accordingly. Given that the extrapolation of the exponential trend of death probabilities would lead to the life expectancy unlimited growth, the control of this procedure is needed. It is well known that there is a natural limit to people life expectancy growth, so the trend extrapolation method could be used only for middle term projections with periodical control and adjustment of the trend to observed life expectancy. Our goal was to avoid this and to bring closer the life expectancy obtained using the best trend estimate method and life expectancy estimated by World Bank experts, that we take as the realistic expectation. In order to overpass this issue to a certain extent, we again used the correction factor to adjust the life expectancy calculated from projected life tables and match it to World Bank life expectancy estimate for a projection period. 
The adjusted projections of probabilities of death were used for the calculation of adjusted trend factors, which enabled us to calculate the death probabilities projections.

\section{The projection results}

The application of described methodologies on the life tables of the Republic of Srpska and the original data from Pension and Disability Insurance Fund of the Republic of Srpska gave us interesting results and enabled us to observe the influence of expected life duration growth on the pension system of Republic of Srpska sustainability. The results are presented in two parts - The life table's estimation and projections and The Pension and Disability Insurance of Republic of Srpska sustainability projections.

\section{The life tables estimation and projections}

The starting point for the estimation and calibration of the probability of death in the Republic of Srpska were the complete life tables of Republic of Croatia from 2016 and calibration of expected life duration to the estimates of World Bank for Bosnia and Herzegovina (Table 1).

Table 1 The current life duration in Republic of Srpska and World Bank estimates of life duration in Bosnia and Herzegovina

\begin{tabular}{|l|c|c|c|}
\hline \multicolumn{1}{|c|}{ Year } & 2006 & 2016 & $2070-2075$ \\
\hline Male & 71.8 & 74.4 & 84.46 \\
Female & 78.32 & 80.1 & 86.91 \\
\hline
\end{tabular}

Source: Authors.

The obtained full life tables for the Republic of Srpska enabled us to make projections of mortality tables for the following 50 years.

After the adjustment of the best estimate trend methodology (according to equations 1 and 2) to meet the future life duration expectations for the Republic of Srpska, the projections of death probabilities are obtained using the above-described methodology. The presentation of the obtained results of projection and the effect of mortality trend (obtained according to equations 1 and 2) are the best done using the aggregate indicator of the death probabilities in a certain year - the expected life duration.

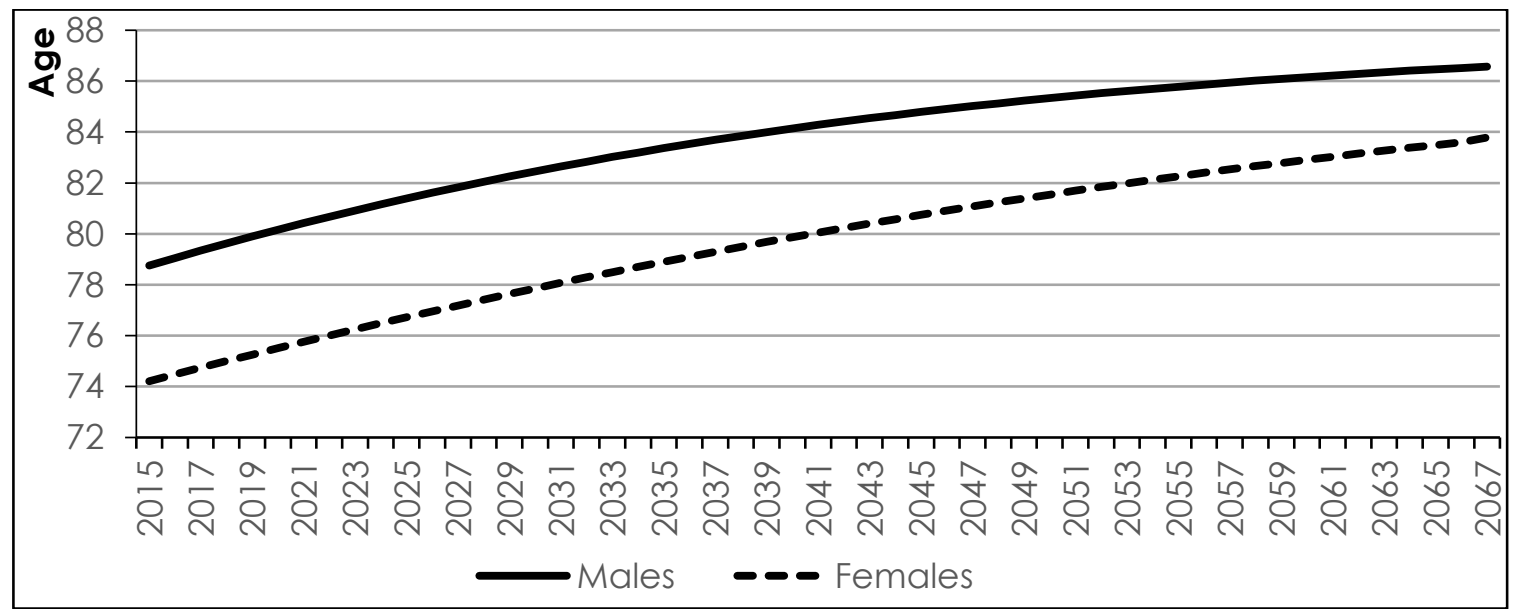

Figure 1 Expected life duration in the Republic of Srpska

Source: Authors' creation. 
The linear growth of the life duration is very well observed in Figure 1, where, on the orthogonal axis, we plot the life expectations for males and females in the Republic of Srpska during the projection period (the horizontal axis).

\section{The employees and pensioners number estimation and projections}

The obtained projections of death probabilities are used to calculate projections of the future number of pensioners and employees in the Republic of Srpska for the period from 2016 to 2066. These projections were obtained by replicating the actuarial projection model previously developed for Pension and Disability Insurance Fund of the Republic of Srpska (Bošnjak, 2016), where the only difference is the incorporation of life tables estimation for Bosnia and Herzegovina and their future projections. The calculations are repeated over the same set of data in order to be able to compare the results of previous research with the results obtained with the inclusion of lifeexpectancy increment.

Figure 2 shows the projections of the number of pension beneficiaries by type of pension) while Figure 3 shows the same projections but observing them by sex.

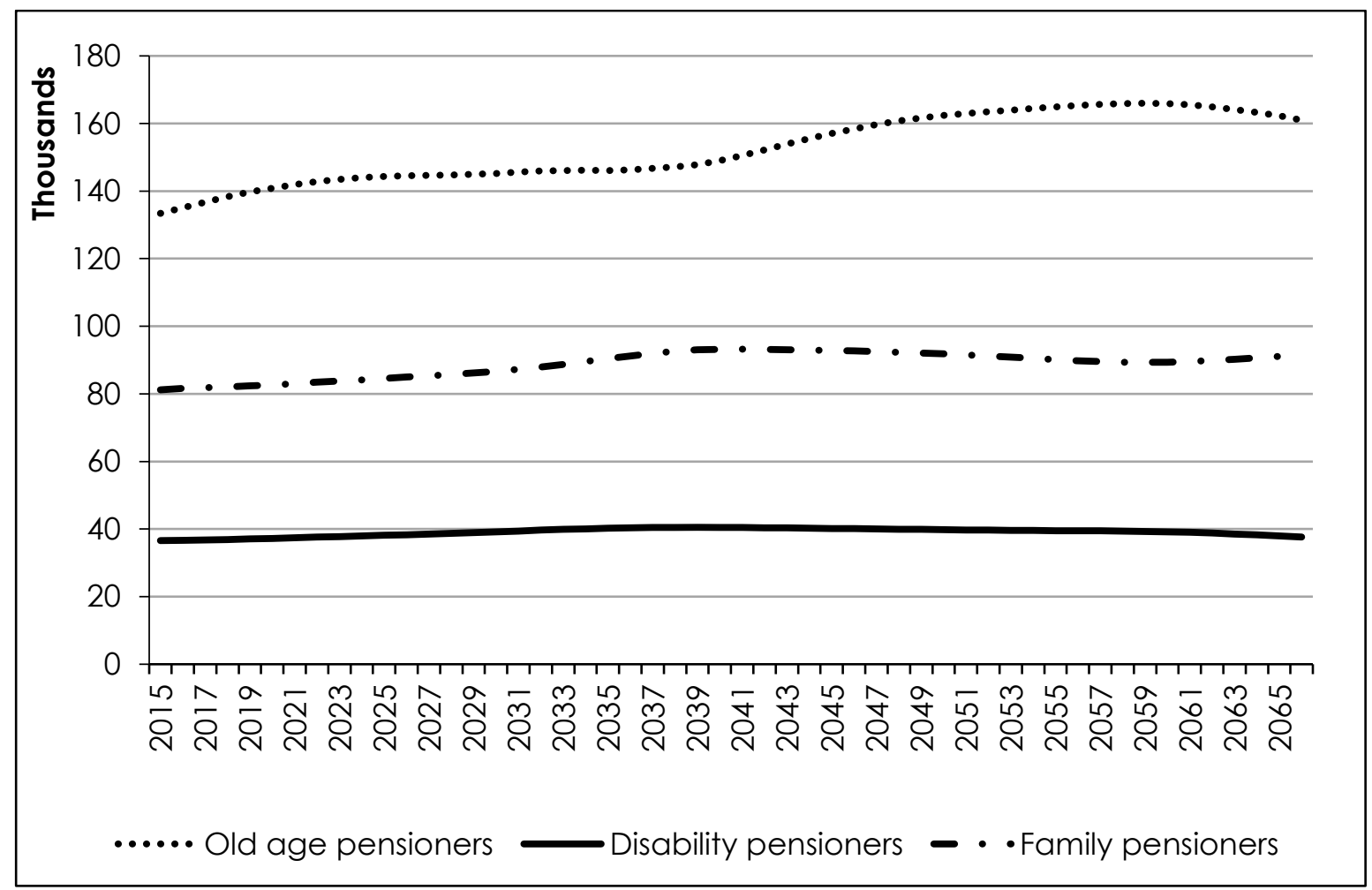

Figure 2 Projections of pensions benefit users' number by pension benefit type Source: Authors' creation.

Trends in the expected number of pension beneficiaries are either constant or increasing, as opposed to the previous research that resulted in a reduction in the number of pension beneficiaries. The detailed comparison will show us the size of the differences. Regarding the observation of male and female pensioners, it was expected that the trend in the number of male pensioners would be steeper than the number of female, due to longer life duration of females. 


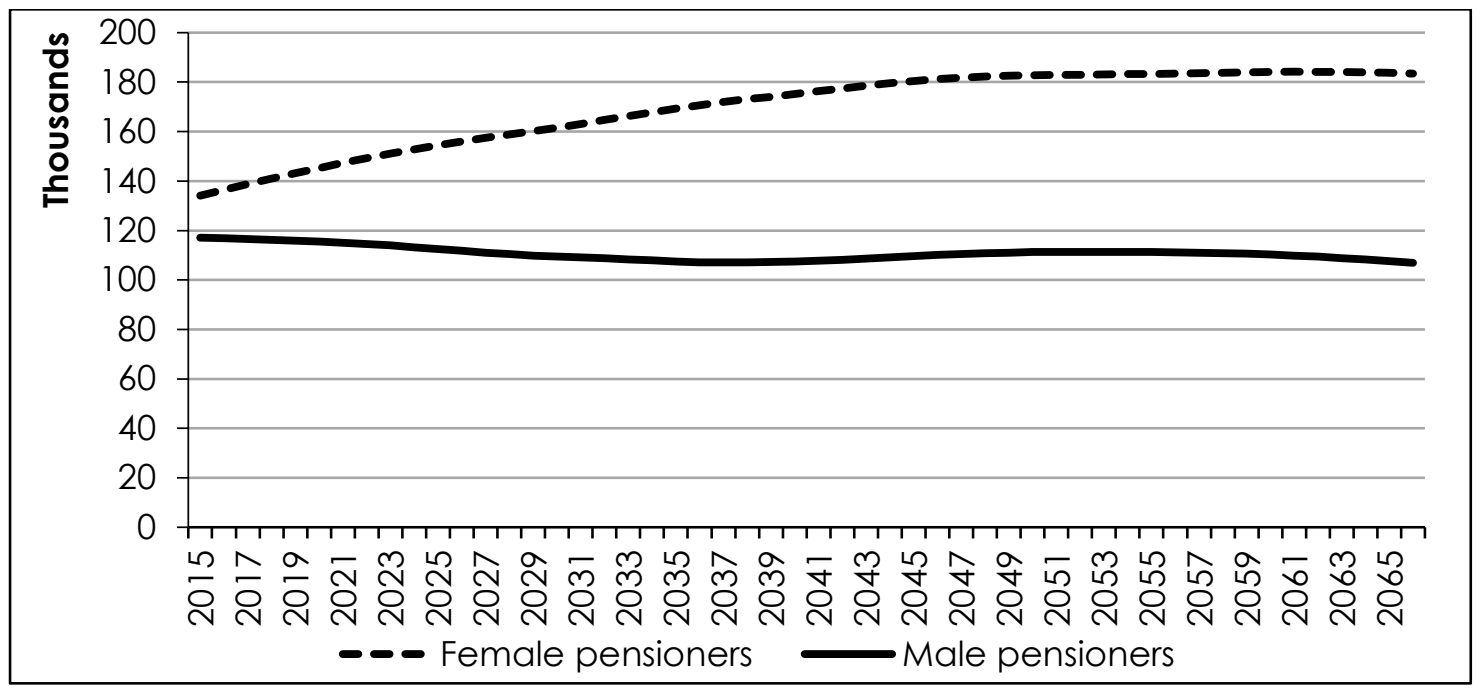

Figure 3 Projections of pensioners' number by sex

Source: Authors. Source: Authors' creation.

Figures 2 and 3 show us the number of pension beneficiaries, but still, in order to see the effects of introducing life table projections, we need to compare these results with the results obtained in the previous calculations.

Figure 4 depicts the "old" projections of the total number of employees and projections obtained using the death probabilities calculated using the best trend estimation methodology. From this figure, we can see the effect of life expectancy increment incorporation into the model. From this figure, we can see the effect of life duration increment incorporated into the model. The projected number of employees will not significantly differ from the previous projections, due to increased life expectancy during the observed period.

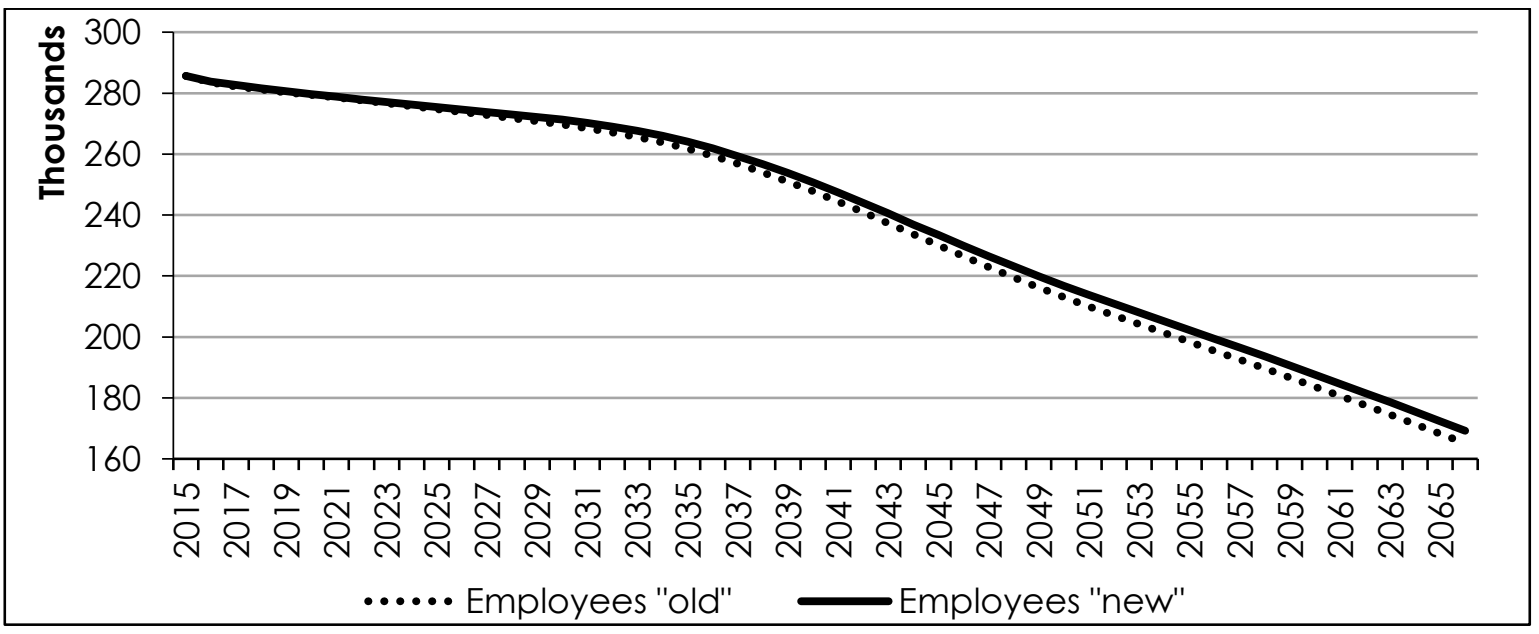

Figure 4 Projections of the total number of employees

Source: Authors' creation.

The reason for this may be the fact that the retirement age limit will not change according to the extended life expectancy, so that reduced mortality will most likely have the greatest impact on age groups of pensioners who will enjoy more in their pension benefits.

The second reason is the fact that we did not change the total number of people expected to enter the group of employees through their first job. We did so to allow a comparison between old and new projections. We kept projections that were made 
for the purposes of our research in 2016, despite the fact that the number of new employees in the Republic of Srpska has been increasing in recent years.

Apart from observing the projection of the number of employees, we are also interested in the effect of assessing and modelling the life table on the number of pensioners, which can be seen in Figure 5.

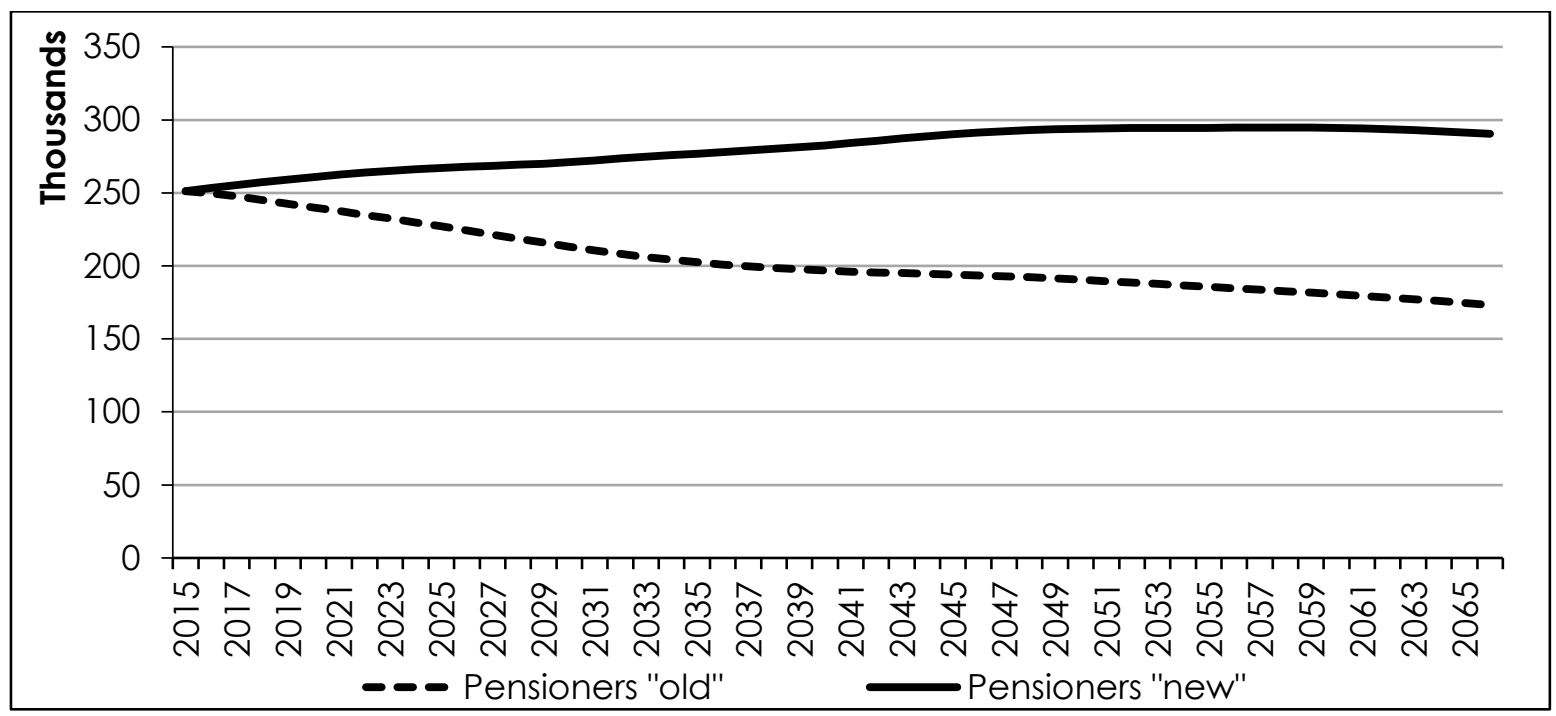

Source: Authors' creation.

The influence of life tables' estimation on projections of the number of pensioners is more than visible in Figure 5. With the application of projected death probabilities, the number of pensioners in future significantly increased as expected due to the growth of life expectancy in the projected period, which had the greatest impact on the group of pension beneficiaries.

\section{The dependency ratio estimation and projections}

From the above-presented results, we have observed that the application of death probabilities adjusted to expect life duration in Bosnia and Herzegovina in the next 50 years would cause an imperceptible increase in the expected number of employees and significant growth in the number of pensioners. As might be expected, if we assume that people will live longer, the number of living in the future will increase, when keeping all other inputs constant.

Nevertheless, we are interested to see the effect of the death probabilities adjustment on the sustainability of Pension and Disability Insurance Fund of the Republic of Srpska. One of the commonly used indicators of sustainability of Pay As You Go pension systems is the dependency ratio, which is calculated as the ratio between a number of passive and active participants of the pension system. It shows the number of pension benefit users which is supported by contributions of one active participant (employee). The Pay As You Go pension systems are designed to function with 3 active participants supporting for one pension benefit user, meaning that the dependency ratio should not be higher than 0.33.

The evidence of the movement of the dependency ratio of the pension system of the Republic of Srpska is shown in Figure 6. 


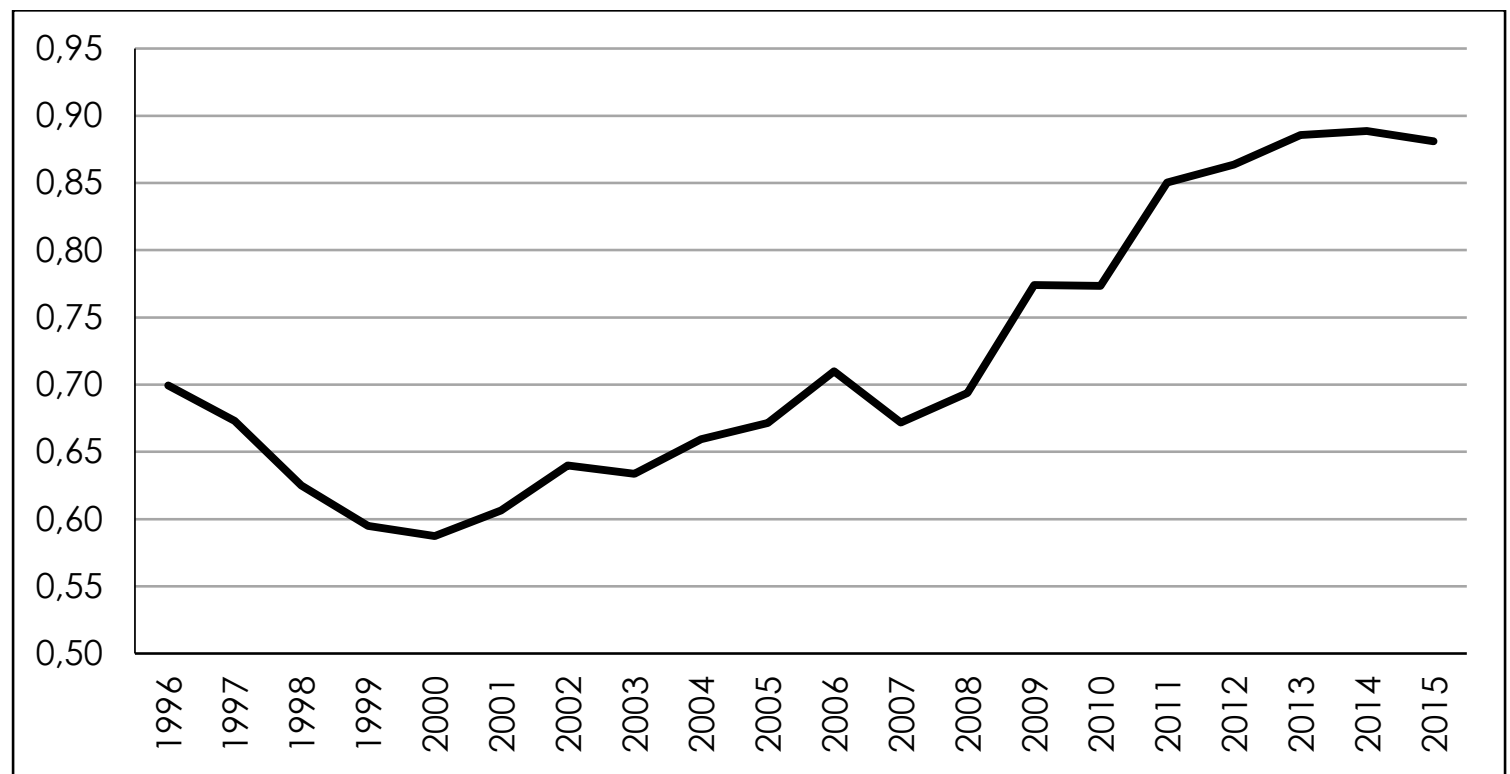

Figure 6 Dependency ratio of Pension and Disability Insurance Fund of Republic of Source: Authors' creation.

As we can observe from the figure, the sustainability of Pension and Disability Insurance Fund of the Republic of Srpska is worsening. Nevertheless, we are interested in the future projections of the dependency ratio. The projections obtained from previous research were not so bright, and the dependency ratio was expected to grow during the projection period. In previous figures, we observed that the inclusion of life tables' projections for the Republic of Srpska caused an increase in the number of pension benefit users in the future, which was not followed by the increment in the number of employees. Still, the effects of the introduction of life table projections in the model and its influence on pension fund dependency ratio is best observable on the graph. Thus, the "new" dependency ratio projections are depicted in Figure 7, together with the "old" projections.

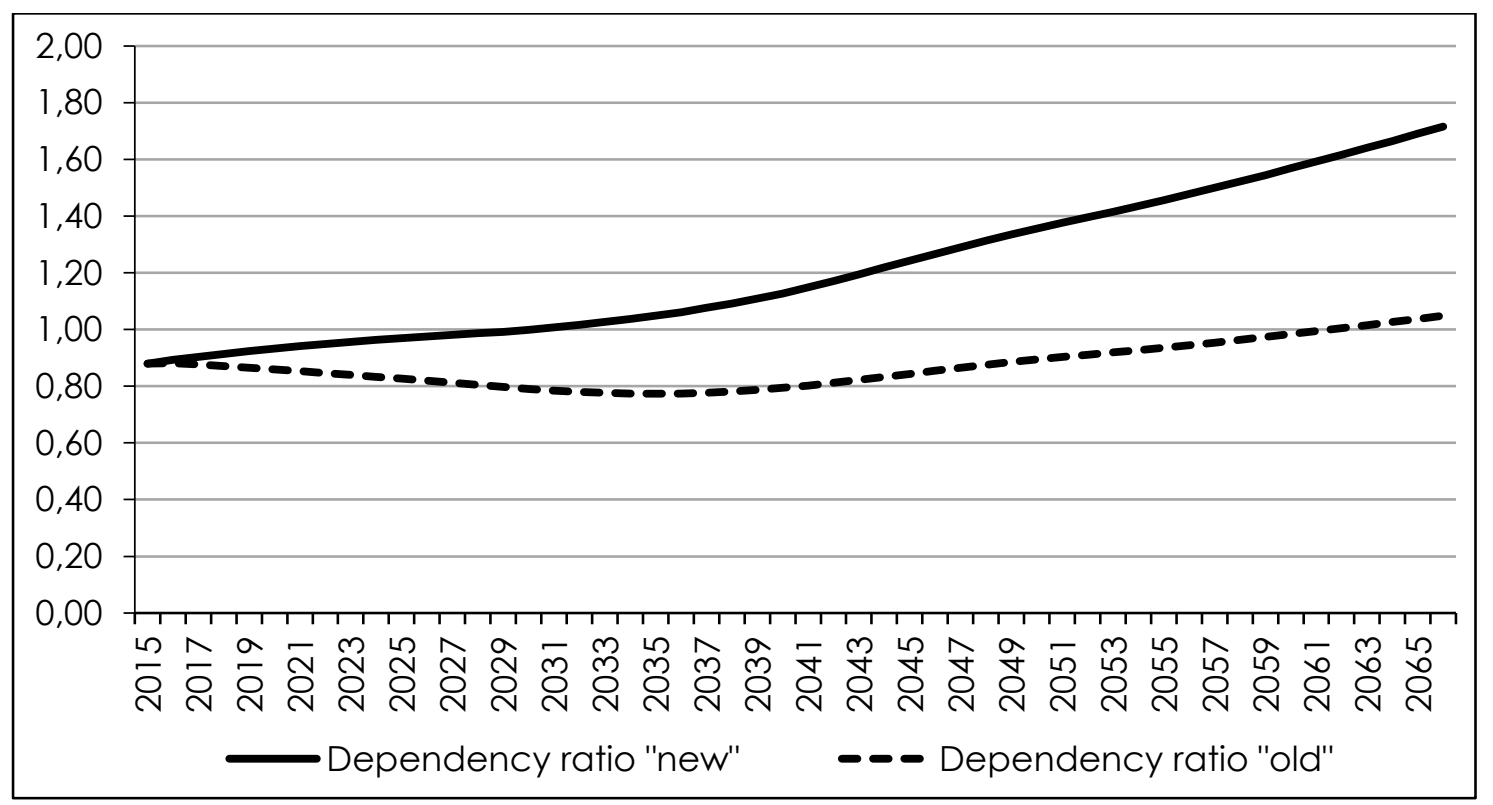

Figure 7 Dependency ratio projections

Source: Authors' creation. 
The future increment of life expectancy has influenced the cohort of pensioners more than the cohort of employees. Thus, the trend of dependency ratio "new" projections is significantly shifted from "old" projections. The dependency ratio will cross the threshold of one (1) much faster than in the case when life expectancy growth is not included in the projections of death probabilities.

Nevertheless, although the application of projected mortality tables showed to have a significant impact on pension fund sustainability, as we expected it would be the case, the further improvements of the model are more than welcome as the new statistical data become available. We remind the reader that the construction of pension fund projection model is a continuous work, which demands a detailed set of data and participation of different experts. Thus, the further improvements of the model and the mortality tables projection research are not only feasible but an obligation.

\section{Conclusion}

The nonexistence of up to date complete life tables and the historical evidence of death probabilities for the Bosnia and Herzegovina and the Republic of Srpska disables the policy planners and many financial institutions to plan adequately and with satisfactory confidence the demographic expectations and to bring the decisions, which are dependent on population projections. The only solution, in this case, is to estimate the complete life tables' death using the life tables of a population with similar demographic characteristics and to use all available information and expert opinion to project it into the future.

That is what we did in this paper, using the abridged life tables of the Republic of Srpska and adjusting them to project the future expected life duration of Bosnia and Herzegovina. By using the best estimate trend, we projected the development of estimated death probabilities for next 50 years and used this projection to replicate the calculation of the expected number of employees and pension benefit users for Pension and Disability Insurance Fund of the Republic of Srpska. The comparison of newly obtained projections and the projections that were done without the estimation and modelling of death probabilities revealed us the impact of the expected growth of life duration in Bosnia and Herzegovina on cohorts of employees and pensioners and consequently on the sustainability of Pension and Disability Insurance Fund of the Republic of Srpska.

As expected, the modification we introduced caused the growth of the expected number of pensioners and employees in future, while their relation and overall pension system sustainability position are best observed through the dependency ratio whose trend did significantly worsen.

The importance of the proper life table usage and their adequate modelling was shown through this simple actuarial model replication. The actuarial projection model for Pension and Disability Insurance Fund of the Republic of Srpska and the data set used for these projections were not changed in comparison to primary research and it represents a significant lack of estimates we obtained, given that the new data on employment and pension retirement are available. Thus, the further upgrade of the model is needed through up to date modelling of employment and retirement probabilities and the expanding the database of employees and pension benefit users used for extraction of all relevant probabilities. 


\section{References}

1. Abramowitz, M. I. A. (1965). Handbook of Mathematical Functions with formulas, Graphs, and Mathematical Tables. Series 55, 4th printing ed. Washington DC: National Bureau of Standards, Applied Mathematics, U.S. Government Printing Office.

2. Booth, T., Tickle, L. (2008). Mortality modelling and forecasting: A review of methods. Annals of Actuarial Science, Vol. 3, No. 1-2, pp. 3-43.

3. Bošnjak, N. (2016). The actuarial projection method for pension fund's dependency ratio in case of Pension and Disability Insurance Fund of Republic of Srpska. Proceedings of the ISCCRO - International Statistical Conference in Croatia (Editors: Dumičić, K., Erjavec, N., Pejić Bach, M.), Zagreb, Croatia, May 05-06, 2016, Zagreb: Croatian Statistical Association, pp. 72-78.

4. ECB Economic Bulletin (2018). The economic impact of population ageing and pension reforms, The European Central Bank.

5. European Commission (2009). Pension schemes and pension projections in the EU-27 Member States - 2008-2060, Volume II - Annex. Brussels: Directorate-Generl for Economic and Financial Affairs Publishing.

6. Holzmann, R. (2009). Ageing population, Pension Funds and Financial Markets. Washington, D.C.: The World Bank.

7. Human Mortality Database (2000). Human Mortality Data Base. Available at: http://www.mortality.org [16 December 2017].

8. Institute for Statistics of Federation of Bosnia and Herzegovina (2017). Detailed life tables of population of Federation of Bosnia and Herzegovina, Sarajevo: Institute for Statistics of Federation of Bosnia and Herzegovina.

9. Institute of Actuaries and Faculty of Actuaries (1990). Continuous Mortality Investigation. Available at https://www.actuaries.org.uk/documents/cmi-report-10-whole-volume [03 January 2018].

10. Institute of Actuaries (2004). Continuous Mortality Investigation Working Paper 3 - Projecting future mortality. Available at https://www.actuaries.org.uk/learn-anddevelop/continuous-mortality-investigation/cmi-working-papers/mortality-projections [03 January 2018].

11. Iyer, S. (1999). Actuarial Mathematics of Social Security Pensions. Geneva: International Labor Office and ISSA.

12. Kostaki, A. (2000). A Relational Technique for Estimating the Age Specific Mortality Pattern from Grouped Data. Mathematical Population Studies, Vol. 9, No. 1, pp. 83-95.

13. Pollard, J. (1989). On the derivation of a full life table from mortality data recorded in fiveyear age groups. Mathematical Population Studies, Vol. 2, No. 1, pp. 1-14.

14. Republic of Srpska Institute of Statistics (2019). Republic of Srpska Institute of Statistics web page. Available at http://www.rzs.rs.ba [20 December 2018].

15. Statistical Office of the Republic of Serbia (2014). Complete life tables for the Republic of Serbia 2010-2012, Belgrade: Statistical Office of the Republic of Serbia.

16. The Working Group for development of Strategy for Pension System in Republic of Srpska, 2010. The Proposal of the Strategy for Pension System Reform in Republic of Srpska, Banja Luka: Republic of Srpska: The Government of Republic of Srpska.

17. The World Bank Data (2018). The World Bank Data. Available at https://data.worldbank.org/indicator/SP.DYN.LEOO.FE.IN?locations=BA [20 December 2018].

18. Waldron, H. (2005). Literature review of long-term mortality projections. Social Security Bulletin, Vol. 66, No. 1, pp. 15-36.

19. Working Group on Ageing Populations and Sustainability (2017). Pension Projections Exercise 2018, Berlin: Bundesministrum fur Arbeit und Soziales. 


\section{About the authors}

Nikolina Bošnjak, PhD, is employed as an assistant professor at the University of Banja Luka where she teaches several courses at the undergraduate and the graduate level. She obtained her Ph.D. from Sapienza University of Rome and continued to conduct her research in the field of actuarial projection models for pension systems as a guest researcher at the Department of Statistics and Operational Research at the University of Vienna. She is the author or co-author of many scientific and research papers and has presented her research at numerous international and national scientific conferences. The author can be contacted at nikolina.bosnjak@ef.unibl.org.

Vesna Prorok, PhD, is employed as an assistant professor at the University of East Sarajevo where she teaches the following courses: Financial Mathematics, Actuarial Mathematics, Econometrics (undergraduate studies); Financial Mathematics and Insurance Analysis (master academic studies). She has authored and co-authored numerous scientific and research papers presented at conferences in Bosnia and Herzegovina and abroad and published in national and international journals in the fields of financial and actuarial mathematics, insurance and econometrics. The author can be contacted at vesna.prorok@ekofis.ves.rs.ba. 